\title{
Retrospective Comparison of Outcomes between Closed and Open Reduction for Developmental Dysplasia of the Hip in Children Aged 6-24 Months
}

\section{Shuyu Ma}

Shengjing Hospital of China Medical University

\section{Weizheng Zhou}

Shengjing Hospital of China Medical University

Lianyong Li ( $D$ loyo_Idy@163.com)

Shengjing Hospital of China Medical University

\section{Enbo Wang}

Shengjing Hospital of China Medical University

\section{Lijun Zhang}

Shengjing Hospital of China Medical University

Qiwei Li

Shengjing Hospital of China Medical University

\section{Research Article}

Keywords: Developmental dysplasia of the hip, Closed reduction, Open reduction, Outcome comparison

Posted Date: October 29th, 2021

DOI: https://doi.org/10.21203/rs.3.rs-1010814/v1

License: (c) (i) This work is licensed under a Creative Commons Attribution 4.0 International License.

Read Full License 


\section{Abstract}

Background: This study aimed to compare the early outcomes between closed reduction (CR) and open reduction (OR) in children aged 6-24 months with developmental dysplasia of the hip (DDH) who could be reduced safely and stably by the closed method.

Methods: We retrospectively reviewed the medical records of 77 patients who underwent CR or OR treatment for DDH from August 2012 to October 2017. Fifty-one patients (56 hips) underwent CR, while 26 (29 hips) underwent OR. The demographic data, International Hip Dysplasia Institute classification, and acetabular index (Al) before reduction were analysed. The centre-edge angle (CEA), Al, Alsberg angle $(\mathrm{AA})$, Reimer's migration index (RMI), and height-to-width index ( $\mathrm{HWI}$ ) of the epiphysis were compared between the CR and OR groups at the final follow-up. The percentages of avascular necrosis (AVN), residual acetabular dysplasia (RAD), $\mathrm{HWI}<0.357, \mathrm{RMI}>33 \%, \mathrm{AA}>81^{\circ}$, and coxa magna $>15 \%$ of the normal side were calculated.

Results: At the final follow up, the mean AA in the CR and OR groups were $77.66^{\circ}\left(60^{\circ}-89^{\circ}\right)$ and $81.97^{\circ}$ $\left(73^{\circ}-91^{\circ}\right)(p=0.001)$, respectively, and there were $32.14 \%$ and $58.62 \%$ of the hips with an AA $>81^{\circ}$ $(p=0.019)$. The frequency of coxa magna $>15 \%$ of the normal side was higher in the OR group $(60.9 \%)$ than in the CR group (6.5\%) $(p<0.001)$. There was no difference in the improvement of Al, CEA, HWI, and $\mathrm{RMI}$ at the final follow-up. The percentages of RAD, $\mathrm{HWI}<0.357, \mathrm{RMI}>33 \%$, and $\mathrm{AVN}$ were not statistically different.

Conclusion: In children aged 6-24 months with DDH, if a stable and safe CR can be obtained but with a widening joint space, an OR may not benefit acetabular remodelling more than a CR procedure, and thus, CR should be attempted.

\section{Introduction}

The purpose of treatment for developmental dysplasia of the hip (DDH) is to obtain and maintain concentric reduction. For irreducible or unstable $\mathrm{DDH}$, open reduction (OR) is the only option.[1] Closed reduction (CR) is still a common treatment method for DDH in patients aged 6-24 months,[2-4] but not all CRs can immediately obtain complete concentricity between the femoral head and acetabulum. Some studies have confirmed that non-concentric $\mathrm{CR}$ occurs for a period of time, but eventual concentric reduction is achieved by femoral head 'docking'.[5, 6] Achievement of an earlier and greater degree of concentric reduction increases the potential of hip restoration and reduces long-term complications and reoperation rate.[7-9] Thus, the indication for CR has become stricter. The majority of physicians believe that a mild joint space or widened medial dye pooling (MDP) is acceptable for a stable CR. $[4,6$, 10] However, due to the different demographics and severity of $D D H$ in $C R$ studies, disparate results have caused some scholars to only accept an outcome of complete concentric reduction.[11, 12] Therefore, there is still considerable controversy regarding acceptable standards for CR treatment for $\mathrm{DDH}$. This is 
due to the dearth of reliable evidence-based research that compares CR and OR and the lack of homogeneity among patients in previous cohorts. $[13,14]$

Within the author's clinical unit, some physicians accept CR that is safe (hip abduction $<65^{\circ}$ that can maintain reduction) and stable (safe zone $>30^{\circ}$ )[15], whereas others only accept complete concentric reduction whose MDP is less than $2 \mathrm{~mm}[11,12]$ on the intraoperative radiography for children aged 6-24 months with DDH. Therefore, some patients with DDH who underwent safe and stable CR required subsequent $\mathrm{OR}$ due to widening of the joint space. These circumstances presented the opportunity to compare the early outcomes of $\mathrm{CR}$ and $\mathrm{OR}$ treatment for $\mathrm{DDH}$ and increase the current understanding of acceptable CR treatment standards. This study aimed to compare the early outcomes between CR and OR in children aged 6-24 months with DDH who can be initially reduced safely and stably by the closed method.

\section{Patients And Methods}

\section{Patient information}

After obtaining the approval of the authors' Institutional Review Board, the medical records were reviewed for all patients who had treatment for DDH between August 2012 and October 2017. Informed consent was obtained from the participants' parents or guardians prior to the study. The included patients were those who can be stably and safely reduced by initial manual operation intraoperatively. However, due to the surgeon's preference, some accepted a certain widening of the joint space, and the patients were then immobilized with a spica cast (CR group), while others accepted a complete reduction. Therefore, a portion of patients underwent subsequent OR (OR group). The other inclusion criteria were as follows: age 6-24 months at the time of reduction, aforementioned CR or OR treatment alone, no treatment before the reduction, and at least 2 years of follow-up. The exclusion criteria included neuromuscular or syndromic hip dysplasia and irreducible or unstable DDH.

The indication for $\mathrm{CR}$ in this group of patients was stable and safe reduction that could be achieved despite a widening joint space on the intraoperative radiography. Stable meant that the safe zone[15] exceeded $30^{\circ}$. Safe meant that the reduction could be maintained after hip abduction of $<65^{\circ}$. If hip abduction was $<70^{\circ}$, percutaneous adductor tenotomy was performed. After a CR treatment was determined intraoperatively, the patient was placed in a spica cast for 3 months followed by an abduction brace for 3 months. In the OR group, the reduction procedure was completed using an anterior approach for all children.[16] Postoperatively, a spica plaster cast was used for 6-8 weeks followed by an abduction brace for 3 months. All treatments were performed by chief paediatric orthopaedic physicians proficient in CR methods and anterior OR surgery.

Following the aforementioned criteria [Fig.1], 79 children were included in the study, including 53 and 26 patients treated with $\mathrm{CR}$ and $\mathrm{OR}$, respectively. Two patients in the CR group continued to have subluxation after brace removal; therefore, OR and pelvic osteotomy were performed at the ages of 3 and 4.5 years, 
respectively. Then, 77 children with successfully treated DDH were compared in the follow-up analysis, including 51 (56 hips) and 26 patients (29 hips) in the CR and OR groups, respectively.

\section{Measurement parameters}

The severity of dislocation before reduction was graded according to the International Hip Dysplasia Institute (IHDI) classification,[17] and the preoperative acetabular index (Al) was measured using anteroposterior(AP) pelvic radiographs. The superior joint space (SJS『and medial joint space (MJS $₫$ were measured on the MRI within 48 hours after reduction. The centre-edge angle (CEA) of Wiberg, Al, Alsberg angle (AA) of the proximal femur (angle between the direction line of the proximal capital physis and the axis of the femoral shaft[18]), Reimer's migration index (RMI),[19] and height-to-width index (HWI) of the epiphysis[20] were measured on the AP pelvic radiograph at the final follow-up. Avascular necrosis (AVN) of the femoral head was evaluated according to Salter's criteria.[21]

During the follow-up period, the reoperation rate due to re-dislocation or residual acetabular dysplasia (RAD) was recorded. At the final follow-up, the frequency of $\mathrm{RAD}, \mathrm{HWI}<0.357, \mathrm{RMI}>33 \%$, and $\mathrm{AA}>81^{\circ}$ were recorded. Moreover, the incidence of coxa magna was recorded and defined as an increase in the width of the epiphyseal nucleus of $>15 \%$ of the normal side.[22] According to the development rule for the Al in normal infants, RAD was defined as an $\mathrm{Al}>26^{\circ}$ in children aged $>48$ months or an $\mathrm{Al}>28^{\circ}$ at an age $\leqq 48$ months. $[23,24]$

\section{Statistical analysis}

SPSS version 25.0 software (IBM, Armonk, New York, USA) was used for statistical processing of the measured data. The Kolmogorov-Smirnov method was used to test the normal distribution of the data. The normal distribution data were expressed in the form of means with ranges, and the non-normal data were expressed in the form of medians accompanied by an interquartile range. Student's t-test (for normal distribution data) or the Mann-Whitney $U$ test (for abnormal distribution) was used to compare the age at reduction, follow-up time, final follow-up age, SJS, MJS, AI, CEA, AA, HWI, and RMI between the $\mathrm{CR}$ and $\mathrm{OR}$ groups. The $c^{2}$ test or Fisher's exact probability test was used to compare the distributions of gender, side, IHDI classification, AVN, RAD, HWI $<0.357, \mathrm{RMI}>33 \%, \mathrm{AA}>81^{\circ}$, and difference in the incidence of epiphyseal enlargement $>15 \%$ at the last follow-up. A $p$-value $<0.05$ was considered statistically significant.

\section{Results}

The demographics of the children in this study are shown in Table 1. There was no significant difference between the CR and OR groups for the distribution of gender, side of the affected hip, age at reduction, follow-up time, or age at the last follow-up. There was a significant difference in the IHDI classification between the two groups $(p=0.048)$. Because the dislocation heights for IHDI types II and III were similar 
with the midpoint of the proximal femoral metaphysis on or below Hilgenreiner's line, there was no significant difference in the degree of dislocation between the two groups when type II and III hips were combined $\left(X^{2}=1.419, p=0.234\right)$. Before reduction, the $\mathrm{Al}$ for the $\mathrm{CR}$ and $\mathrm{OR}$ groups were average $37.30^{\circ}\left(22^{\circ}-50^{\circ}\right)$ and $36.45^{\circ}\left(27^{\circ}-45^{\circ}\right)$, respectively $(t=0.611, p=0.543)$.

42 (46 hips) and 26 patients' (29 hips) intact MRI images within 48 hours after operation in the CR and OR groups were measured, respectively. The average SJS (Student's t-test, $t=2.126 ; p=0.037$ ) and MSJ (Student's t-test, $t=2.086 ; p=0.040$ ) in OR group were obviously less than that in CR group (Table 2).

During the final follow-up, two hips in two children with persistent subluxation in the CR group underwent a second reduction operation. Therefore, the re-dislocation rate was $3.77 \%(2 / 53)$ in the CR group. No redislocation occurred in the OR group. At the final follow-up, the Al in the OR group was slightly higher than that in the CR group (Table 3). The Al in the CR and OR groups was significantly improved compared with the Al before reduction (paired sample t-test, $t=12.69$ and 6.40 , respectively; $p=0.001$ ). The average Al improvements were $11.96^{\circ}\left(-8^{\circ}-31^{\circ}\right)$ and $8.76^{\circ}\left(0^{\circ}-28^{\circ}\right)$ in the CR and OR groups (Student's t-test, $t=1.956, p=0.054)$, respectively.

At the last follow-up, there was no significant difference between the two groups for CEA, HWI, and RMl; however, the AA in the OR group was significantly higher than that in the CR group (Table 3, Fig.2, 3). The incidence of $A A>81^{\circ}$ was higher in the OR group than in the CR group $\left(X^{2}=5.530, p=0.019\right.$, Table 4$)$.

According to Salter's criteria, [21] AVN was found in 15 (26.79\%) and $10(34.48 \%)$ hips in the CR and OR groups, respectively $\left(X^{2}=0.545, p=0.460\right)$. In patients with unilateral $\mathrm{DDH}$, the frequencies of the coxa magna ( $>15 \%$ of the normal side) were $6.5 \%(3 / 46)$ and $60.9 \%(14 / 23)$ in the CR and OR groups (continuous correction $X^{2}$ test, $X^{2}=21.553, p<0.001$ ), respectively[Fig.2,3].

\section{Discussion}

Complete concentric reduction of the femoral head and acetabulum is a necessary condition for the normal development of the hip joint. Stable CR with an MDP of $<4 \mathrm{~mm}$ can obtain good long-term results. $[25,26]$ We couldn't compare the MDP statistically between the groups because there were no scales on the intraoperative radiography. However, the average MJS on postoperative MRI in OR group is close to $2 \mathrm{~mm}$ which is apparently less than that in CR group. The factors that affect the quality of CR include abnormal bony, cartilaginous, and soft tissue structure. The CR standard for safety and stability in our study combined the effects of these pathological factors. For the first time, this study compared the results of $\mathrm{OR}$ and $\mathrm{CR}$ under the similar degree of DDH reducibility and excluded the influence of different baseline factors before reduction.

The shaping ability of the acetabulum is an important internal factor for normal development of the hip joint after $\mathrm{CR}$ or OR. The Al is an important index for the morphological development of the acetabulum and an important reference for the prognosis of reoperation intervention and long-term osteoarthritis. 
Generally, the Al of normal infants decreases continuously before the age of 4 , which is the peak of development. After the age of 4 , development enters the platform stage.[23, 24] The key period of acetabulum shaping is 2 years after DDH reduction,[27] and the shaping ability is obviously weakened by the age of 4 years. $[28,29]$ Therefore, CR should be performed in patients aged $<2$ years to make full use of the self-shaping ability of the acetabulum.[2-4]. The average age at the final follow-up in our study was $>48$ months, allowing us to fully compare acetabulum shaping between the groups. It is traditionally believed that fully concentric reduction can be restored early and to the greatest extent through OR, which may benefit acetabular remodelling. However, the current results indicated that the improvement of $\mathrm{Al}$, incidence of RAD, CEA, and RMI were not different between CR and OR when the reducibility was similar; therefore, our results demonstrate that a safe and stable CR is acceptable in children aged 6-24 months. [6]

Re-dislocation is a common complication of $\mathrm{CR}$ or $\mathrm{OR}$. The reported re-dislocation rates vary between $0 \%$ and $18 \% .[4,30,31]$ In a multicentre, prospective study, a re-dislocation rate of $9 \%$ after CR was reported. [32] In the CR group of our study, the subluxation rate was $3.77 \%$. This may be related to our emphasis on the stability of reduction (safe zone $>30^{\circ}$ ) and shows that the stability was important for the maintenance of reduction. Although OR can maximize the stability after reduction, up to $14 \%$ of the patients may present with re-dislocation. $[33,34]$ There was no re-dislocation in our OR group, which may be related to the small sample size and biased sample selection.

Previous studies have suggested that OR increases the risk of osteonecrosis,[31, 35] but other studies do not support this conclusion.[10,36] Here, there was no significant difference in the presence of AVN between the two groups. Because of the lack of follow-up to bone maturity, the KalamchiMacEwen[33] method could not be used for accurate typing of AVN.

An increase of coxa magna after DDH reduction is a manifestation of developmental disorders. If the increase in the width of the epiphyseal nucleus of the femoral head is $>15 \%$ of the normal side, it may eventually lead to adverse consequences.[22,37] Our study indicated that overgrowth of the femoral head was related to OR. Imatani et al.[37] observed that even if children receiving OR had concentric and matched reduction, excessive growth of the femoral head cartilage occurred several months postoperatively and resulted in a poorer prognosis. Excessive growth after OR may be related to the abnormal mechanical stress caused by acetabular dysplasia or subluxation[22] and/or induction of synovitis in the hip joint that may increase the vascularization of the femoral head, activate chondrocytes, and lead to overgrowth of the femoral head.[38, 39] Furthermore, overgrowth of the femoral head may be related to changes in microcirculation within the proximal femur after OR; however, more studies are needed to confirm this.

The orientation of the proximal femur epiphysis (OPFE) is an important reference for the morphological development of the proximal femur and serves as the basis for the diagnosis and early surgical intervention of Kalamchi-MacEwen type II developmental disturbance.[33, 40] The AA can be used as an index to measure OPFE. In children with successful $C R$, the AA reached the level found in normal children 
(approximately $73^{\circ}$ ) by the age of 5.[18] Here, the increased AA in the OR group [Fig.3] indicated that OR interfered with the development of the OPFE, which has not been reported previously. Special attention should be paid to long-term follow-up for patients with DDH who undergo OR to determine the incidence of type Il development disorder during the bone maturation period.

Our study has the following limitations. First, a retrospective study inevitably presents selective bias. Second, we only compared the AI and IHDI classification of the two groups before reduction; thus, other pathological factors may have hindered reduction. Third, with short-term follow-up, the hip joint did not reach the mature developmental state, making it impossible to accurately compare AVN and the reoperation rate of the two groups. Fourth, bilateral DDH is an important factor for poor prognosis; however, here, there were few bilateral cases, and stratified analysis was not possible. Therefore, it was not clear whether there were differences in the outcomes of CR or OR in bilateral DDH. Fifth, OR can increase stability after reduction and maintain the reduction with a relatively small abduction angle, but this effect was not specifically evaluated.

In summary, although OR can achieve maximum concentric reduction, it had a potential risk leading to development disturbance of the proximal femur, due to the invasiveness of $\mathrm{OR}$ and the vulnerability of the femoral head in infants and young children. In children aged 6-24 months with DDH, if a stable and safe CR can be obtained but with a widening joint space, an OR may not benefit acetabular remodelling more than a CR procedure. Therefore, CR should be attempted for these patients firstly, although further research is warranted to determine the long-term outcomes of CR and OR.

\section{Declarations}

\section{Ethics approval and consent to participate}

This study was approved by the Medical Ethics Committee of the authors' institution (Approval No. 2020PS113K). We confirm that all methods were performed in accordance with the relevant guidelines and regulations.

\section{Consent for publication}

All the parents or guardians of the patients included in this study have signed informed consent form before participation.

\section{Availability of data and materials}

All data generated or analyzed during the current study are included in this published article, and the further details are available from the corresponding author. 


\section{Competing interests}

The authors declare that they have no competing interests

\section{Funding}

This work was supported by National Nature Science Foundation of China (Grant number: 81772296).

\section{Authors' contributions}

Shuyu Ma: data collection and analysis, manuscript preparation.

Weizheng Zhou: data collection and analysis, manuscript preparation.

Lianyong Li: project administration, manuscript revision, fund acquisition.

Enbo Wang: data collection and analysis.

Lijun Zhang: data analysis, manuscript revision.

Qiwei Li: data analysis, manuscript revision.

\section{Acknowledgements}

Not applicable

\section{References}

1. Vitale MG, Skaggs DL. Developmental dysplasia of the hip from six months to four years of age. J Am Acad Orthop Surg. 2001;9(6):401-11.

2. Li Y, Zhou Q, Liu Y, Chen W, Li J, Canavese F, et al. Closed reduction and dynamic cast immobilization in patients with developmental dysplasia of the hip between 6 and 24 months of age. Eur $\mathrm{J}$ Orthop Surg Traumatol. 2019;29(1):51-7.

3. Alassaf N. Treatment of developmental dysplasia of the hip (DDH) between the age of 18 and 24 months. Eur J Orthop Surg Traumatol. 2020;30(4):637-41.

4. Tennant SJ, Eastwood DM, Calder P, Hashemi-Nejad A, Catterall A. A protocol for the use of closed reduction in children with developmental dysplasia of the hip incorporating open psoas and adductor releases and a short-leg cast: Mid-term outcomes in 113 hips. Bone Joint J. 2016;98-B(11):1548-53.

5. Talathi NS, Chauvin NA, Sankar WN. Docking of the femoral head following closed reduction for DDH: Does it really occur. J Pediatr Orthop. 2018;38(8):e440-440e445. 
6. Zhou W, Sankar WN, Zhang F, Li L, Zhang L, Zhao Q. Evolution of concentricity after closed reduction in developmental dysplasia of the hip. Bone Joint J. 2020;102-B(5):618-26.

7. Vaquero-Picado A, González-Morán G, Garay EG, Moraleda L. Developmental dysplasia of the hip: update of management. EFORT Open Rev. 2019;4(9):548-56.

8. Li Y, Xu H, Li J, Yu L, Liu Y, Southern E, et al. Early predictors of acetabular growth after closed reduction in late detected developmental dysplasia of the hip. J Pediatr Orthop B. 2015;24(1):35-9.

9. Cooper AP, Doddabasappa SN, Mulpuri K. Evidence-based management of developmental dysplasia of the hip. Orthop Clin North Am. 2014;45(3):341-54.

10. Novais EN, Hill MK, Carry PM, Heyn PC. Is age or surgical approach associated with osteonecrosis in patients with developmental dysplasia of the hip? A Meta-analysis. Clin Orthop Relat Res. 2016;474(5):1166-77.

11. Alsiddiky AM, Bakarman KA, Alzain KO, Aljassir FF, Al-Ahaideb AS, Kremli MK, et al. The early detection and management of unstable concentric closed reduction of DDH with percutaneous Kwire fixation in infants 6 to 12 months of age. J Pediatr Orthop. 2012;32(1):64-9.

12. Tarassoli P, Gargan MF, Atherton WG, Thomas SR. The medial approach for the treatment of children with developmental dysplasia of the hip. Bone Joint J. 2014;96-B(3):406-13.

13. Tennant SJ, Hashemi-Nejad A, Calder P, Eastwood DM. Bilateral developmental dysplasia of the hip: does closed reduction have a role in management? Outcome of closed and open reduction in 92 hips. J Pediatr Orthop. 2019;39(4):e264-264e271.

14. Abousamra O, Deliberato D, Singh S, Klingele KE. Closed vs open reduction in developmental dysplasia of the hip: The short-term effect on acetabular remodeling. J Clin Orthop Trauma. 2020;11(2):213-6.

15. Ramsey PL, Lasser S, MacEwen GD. Congenital dislocation of the hip: use of the Pavlik harness in the child during the first six months of life. 1976. J Bone Joint Surg Am. 2002;84(8):1478; discussion 1478.

16. Dhar S, Taylor JF, Jones WA, Owen R. Early open reduction for congenital dislocation of the hip. J Bone Joint Surg Br. 1990;72(2):175-80.

17. Narayanan U, Mulpuri K, Sankar WN, Clarke NM, Hosalkar H, Price CT, et al. Reliability of a new radiographic classification for developmental dysplasia of the hip. J Pediatr Orthop. 2015;35(5):478-84.

18. Gui R, Canavese F, Liu S, Li L, Zhang L, Li Q. The potential role of the Alsberg angle as a predictor of lateral growth disturbance of the capital femoral epiphysis in children with developmental dysplasia of the hip treated by closed reduction. J Child Orthop. 2020;14(2):106-11.

19. Reimers $\mathrm{J}$. The stability of the hip in children. A radiological study of the results of muscle surgery in cerebral palsy. Acta Orthop Scand Suppl. 1980;184:1-100.

20. Casaletto JA, Perry DC, Foster A, Bass A, Bruce CE. The height-to-width index for the assessment of femoral head deformity following osteonecrosis in the treatment of developmental dysplasia. J Bone Joint Surg Am. 2009;91(12):2915-21. 
21. Salter RB, Kostuik J, Dallas S. Avascular necrosis of the femoral head as a complication of treatment for congenital dislocation of the hip in young children: a clinical and experimental investigation. Can J Surg. 1969;12(1):44-61.

22. Gamble JG, Mochizuki C, Bleck EE, Rinsky LA. Coxa magna following surgical treatment of congenital hip dislocation. J Pediatr Orthop. 1985;5(5):528-33.

23. Li LY, Zhang LJ, Li QW, Zhao Q, Jia JY, Huang T. Development of the osseous and cartilaginous acetabular index in normal children and those with developmental dysplasia of the hip: a crosssectional study using MRI. J Bone Joint Surg Br. 2012;94(12):1625-31.

24. Tönnis D. Normal values of the hip joint for the evaluation of X-rays in children and adults. Clin Orthop Relat Res. 1976;(119):39-47.

25. Drummond DS, O'Donnell J, Breed A, Albert MJ, Robertson WW. Arthrography in the evaluation of congenital dislocation of the hip. Clin Orthop Relat Res. 1989;(243):148-56.

26. Lönnerholm T. Arthrography of the hip in children. Technique, normal anatomy and findings in unstable hip joints. Acta Radiol Diagn (Stockh). 1980;21(2):279-92.

27. Albinana J, Dolan LA, Spratt KF, Morcuende J, Meyer MD, Weinstein SL. Acetabular dysplasia after treatment for developmental dysplasia of the hip. Implications for secondary procedures. J Bone Joint Surg Br. 2004;86(6):876-86.

28. Shin $\mathrm{CH}$, Yoo WJ, Park MS, Kim JH, Choi IH, Cho TJ. Acetabular remodeling and role of osteotomy after closed reduction of developmental dysplasia of the hip. J Bone Joint Surg Am. 2016;98(11):952-7.

29. Chen IH, Kuo KN, Lubicky JP. Prognosticating factors in acetabular development following reduction of developmental dysplasia of the hip. J Pediatr Orthop. 1994;14(1):3-8.

30. Murray T, Cooperman DR, Thompson GH, Ballock T. Closed reduction for treatment of development dysplasia of the hip in children. Am J Orthop (Belle Mead NJ). 2007;36(2):82-4.

31. Pospischill R, Weninger J, Ganger R, Altenhuber J, Grill F. Does open reduction of the developmental dislocated hip increase the risk of osteonecrosis. Clin Orthop Relat Res. 2012;470(1):250-60.

32. Sankar WN, Gornitzky AL, Clarke N, Herrera-Soto JA, Kelley SP, Matheney T, et al. Closed reduction for developmental dysplasia of the hip: early-term results from a prospective, multicenter cohort. $J$ Pediatr Orthop. 2019;39(3):111-8.

33. Kalamchi A, MacEwen GD. Avascular necrosis following treatment of congenital dislocation of the hip. J Bone Joint Surg Am. 1980;62(6):876-88.

34. McCluskey WP, Bassett GS, Mora-Garcia G, MacEwen GD. Treatment of failed open reduction for congenital dislocation of the hip. J Pediatr Orthop. 1989;9(6):633-9.

35. Firth GB, Robertson AJ, Schepers A, Fatti L. Developmental dysplasia of the hip: open reduction as a risk factor for substantial osteonecrosis. Clin Orthop Relat Res. 2010;468(9):2485-94.

36. Thomas IH, Dunin AJ, Cole WG, Menelaus MB. Avascular necrosis after open reduction for congenital dislocation of the hip: analysis of causative factors and natural history. J Pediatr Orthop. 
1989;9(5):525-31.

37. Imatani J, Miyake Y, Nakatsuka Y, Akazawa H, Mitani S. Coxa magna after open reduction for developmental dislocation of the hip. J Pediatr Orthop. 1995;15(3):337-41.

38. Gershuni-Gordon DH, Axer A. Synovitis of the hip joint-an experimental model in rabbits. J Bone Joint Surg BrThe Journal of bone and joint surgery. British volume. 1974.

39. Hoaglund FT. Experimental hemarthrosis. The response of canine knees to injections of autologous blood. J Bone Joint Surg Am. 1967;49(2):285-98.

40. Shin $\mathrm{CH}$, Hong WK, Lee DJ, Yoo WJ, Choi IH, Cho TJ. Percutaneous medial hemi-epiphysiodesis using a transphyseal screw for caput valgum associated with developmental dysplasia of the hip. BMC Musculoskelet Disord. 2017;18(1):451.

\section{Tables}

Table 1

Comparison of demographic data between the closed and open reduction groups 


\begin{tabular}{|c|c|c|c|c|}
\hline & & $\begin{array}{l}\text { Closed Reduction } \\
\text { (56 hips) }\end{array}$ & $\begin{array}{l}\text { Open Reduction } \\
\text { (29 hips) }\end{array}$ & $p$ value \\
\hline \multirow[t]{2}{*}{ Sex } & Male (\%) & $7(13.7)$ & $1(3.8)$ & \multirow[t]{2}{*}{$0.343^{a}$} \\
\hline & Female (\%) & $44(86.3)$ & $25(96.2)$ & \\
\hline \multirow[t]{3}{*}{ Side } & Left (\%) & $30(58.8)$ & 15 (57.7) & \multirow[t]{3}{*}{$0.973^{a}$} \\
\hline & Right (\%) & $16(31.4)$ & $8(30.8)$ & \\
\hline & Bilateral (\%) & $5(9.8)$ & $3(11.5)$ & \\
\hline \multirow[t]{3}{*}{ IHDI grade } & Type II (\%) & $9(16.1)$ & $0(0)$ & \multirow[t]{3}{*}{$0.048^{b}$} \\
\hline & Type III (\%) & $31(55.4)$ & $17(58.6)$ & \\
\hline & Type IV (\%) & $16(28.6)$ & $12(41.4)$ & \\
\hline \multicolumn{2}{|c|}{$\begin{array}{l}\text { Age at reduction (mos) } \\
\text { (range; SD) }\end{array}$} & $13.16(6 \sim 23 ; 4.85)$ & $14.73(6 \sim 24 ; 5.30)$ & $0.196^{c}$ \\
\hline \multicolumn{2}{|c|}{$\begin{array}{l}\text { Duration of follow up (mos) } \\
\text { (range; SD/ Median) }\end{array}$} & $39.63(24 \sim 74 ; 14.27)$ & $25(24 \sim 74 ; 25)^{\mathrm{e}}$ & $0.109^{d}$ \\
\hline \multicolumn{2}{|c|}{$\begin{array}{l}\text { Age at final follow up (mos) } \\
\text { (range; SD) }\end{array}$} & $52.78(30 \sim 90 ; 14.41)$ & $49.85(30 \sim 83 ; 14.74)$ & $0.404^{c}$ \\
\hline \multicolumn{5}{|c|}{$\begin{array}{l}\text { Note: for calculation of each } p \text {-value in the table, a chi-square test is used, b Fisher's exact probability } \\
\text { test is used, c two independent sample t-test is used, } d \text { Mann Whitney } U \text { test is used; e is the median } \\
\text { of reorganization data; IHDI, International Hip Dysplasia Institute. }\end{array}$} \\
\hline
\end{tabular}

Table 2

Comparison of SJS and MJS between the closed and open reduction groups on MRI within 48 hours after operation 


\begin{tabular}{|llll|}
\hline & $\begin{array}{l}\text { Closed Reduction } \\
(46 \text { hips })\end{array}$ & $\begin{array}{l}\text { Open Reduction } \\
(29 \text { hips })\end{array}$ & $p$ value \\
\hline Superior joint space $(\mathrm{mm})$ & 5.39 & 4.83 & 0.037 \\
& $(2.25 \sim 8.28 ; 1.24)$ & $(3.09 \sim 6.59 ; 0.87)$ & \\
\hline Medial joint space $(\mathrm{mm})$ & 3.44 & 2.83 & 0.040 \\
& $(1.25 \sim 6.75 ; 1.35)$ & $(1.02 \sim 5.27 ; 1.05)$ & \\
\hline $\begin{array}{l}\text { Note: Data are presented as the mean (range; standard deviation), each } p \text {-value in the table is } \\
\text { calculated by two independent-samples } t \text {-test. }\end{array}$ & \\
\hline
\end{tabular}

Table 3

Comparison of the measurements between the closed and open reduction groups at the final follow-up

\begin{tabular}{|llll|}
\hline & $\begin{array}{l}\text { Closed Reduction } \\
(56 \text { hips })\end{array}$ & $\begin{array}{l}\text { Open Reduction } \\
(29 \text { hips })\end{array}$ & $p$ value \\
\hline Acetabular index $\left(^{\circ}\right)$ & 25.34 & 27.69 & 0.027 \\
& $(14 \sim 36 ; 4.74)$ & $(21 \sim 36 ; 4.19)$ & \\
\hline Centre-edge angle $\left(^{\circ}\right)$ & 12.61 & 10.45 & 0.212 \\
& $(-9 \sim 26 ; 8.30)$ & $(0 \sim 23 ; 5.58)$ & 0.001 \\
\hline Alsberg angle $\left(^{\circ}\right)$ & 77.66 & 81.97 & 0.746 \\
\hline Height-to-width index & $(60 \sim 89 ; 6.84)$ & $(73 \sim 91 ; 4.33)$ & \\
& 0.46 & 0.46 & 0.081 \\
\hline Reimer's migration index $(\%)$ & $(0.24 \sim 0.59 ; 0.07)$ & $(0.37 \sim 0.57 ; 0.05)$ & \\
\hline $\begin{array}{l}\text { Note: Data are presented as the mean }(\text { range; standard deviation), each } p \text {-value in the table is } \\
\text { calculated by two independent-samples } t \text {-test. }\end{array}$ & 30.23 & \\
\hline
\end{tabular}

Table 4

Morphological comparison of the hip joints between the closed and open reduction groups at the final follow-up 


\begin{tabular}{|c|c|c|c|c|}
\hline & & Closed Reduction & Open Reduction & $p$ value \\
\hline & & Number (\%) & Number (\%) & \\
\hline \multirow[t]{2}{*}{ Residual acetabular dysplasia } & positive & $18(32.14)$ & $14(48.28)$ & \multirow[t]{2}{*}{0.146} \\
\hline & negative & $38(67.86)$ & $15(51.72)$ & \\
\hline \multirow[t]{2}{*}{ Height-to-width index } & $\geq 0.357$ & $52(92.86)$ & $29(100)$ & \multirow[t]{2}{*}{$0.294^{*}$} \\
\hline & $<0.357$ & $4(7.14)$ & $0(0)$ & \\
\hline \multirow[t]{2}{*}{ Alsberg angle } & $\leq 81^{\circ}$ & $38(67.86)$ & $12(41.38)$ & \multirow[t]{2}{*}{0.019} \\
\hline & $>81^{\circ}$ & $18(32.14)$ & $17(58.62)$ & \\
\hline \multirow[t]{2}{*}{ Reimer's migration index } & $\leq 33 \%$ & $40(71.43)$ & $15(51.72)$ & \multirow[t]{2}{*}{0.071} \\
\hline & $>33 \%$ & $16(28.57)$ & $14(48.28)$ & \\
\hline
\end{tabular}

\section{Figures}

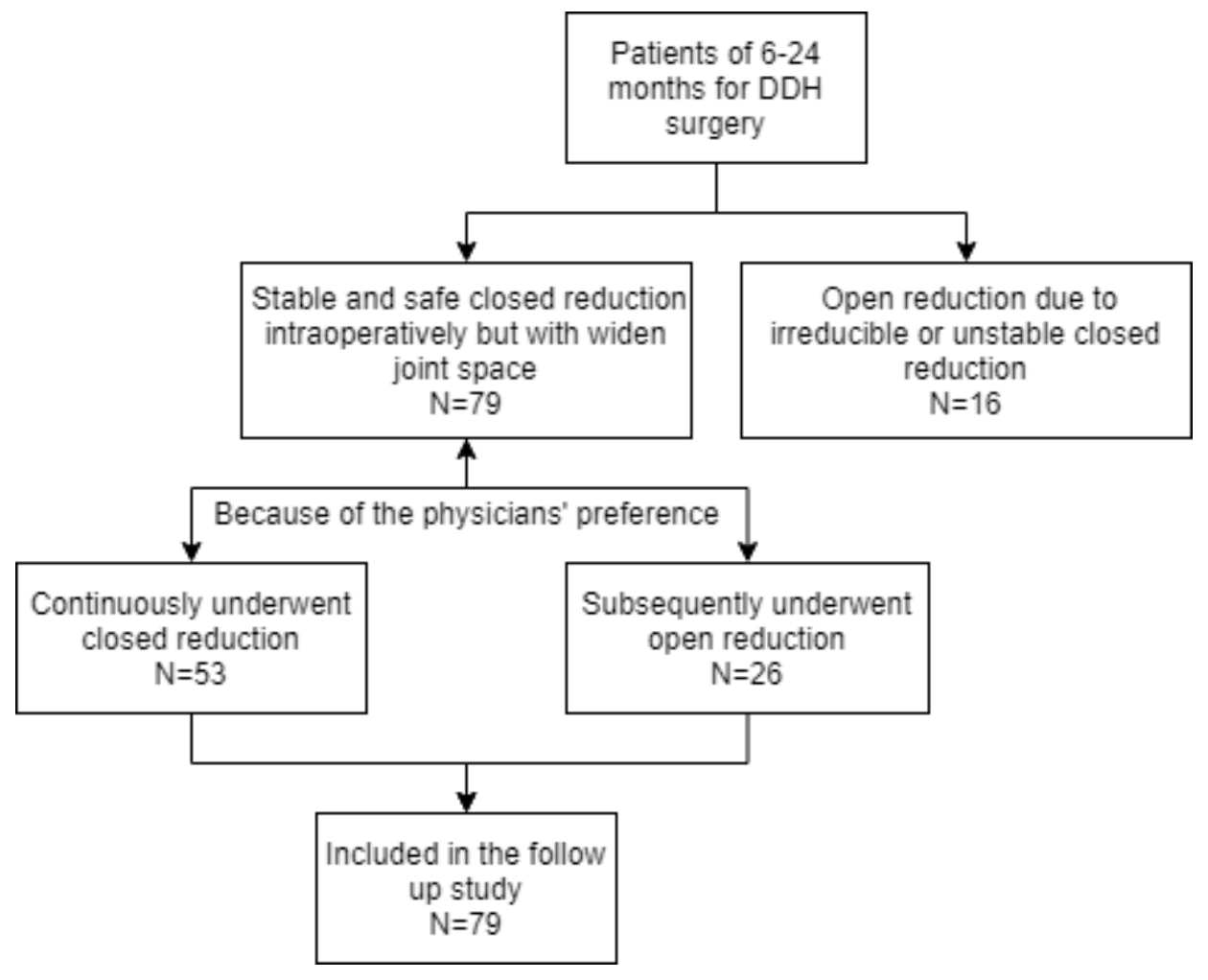

\section{Figure 1}

This drawing is a flow chart showing how patients included into this study 


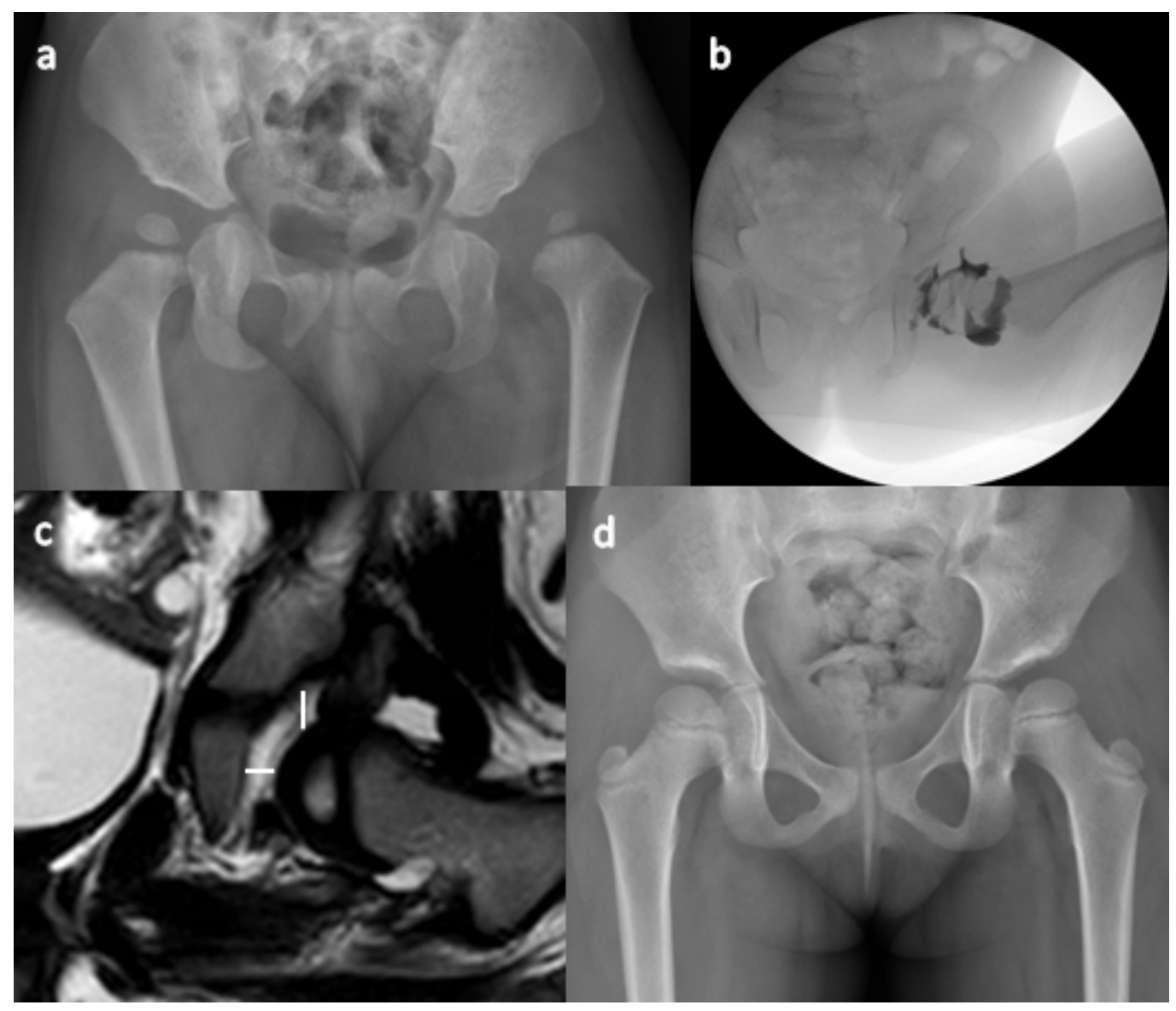

Figure 2

A girl of 15-month old with developmental dysplasia of the hip in the left hip underwent closed reduction. a: Preoperative anteroposterior pelvic radiograph; $b$ : Intraoperative arthrogram after closed reduction; c: Postoperative MRI during 48 hours, the superior and medial joint space were $5.31 \mathrm{~mm}$ and $3.75 \mathrm{~mm}$, respectively; d: Anteroposterior pelvic radiograph 45 months after surgery; Shenton's line was intact; the shape and size of the femoral head were similar to that of the contralateral side; acetabular index is $23^{\circ}$; alsberg angle is $79^{\circ}$ 


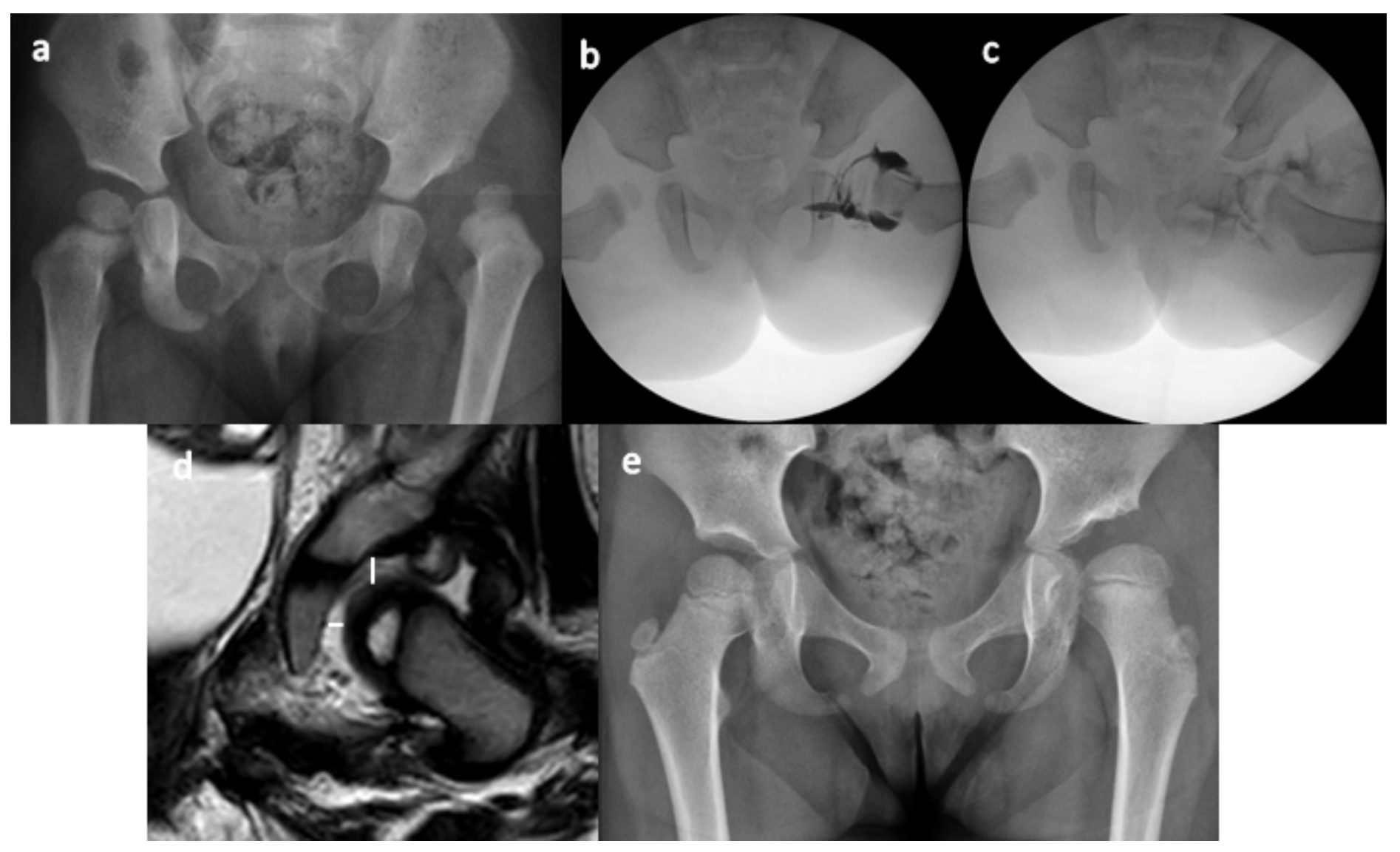

\section{Figure 3}

Female, 14 months old, open reduction for DDH in the left hip a: Preoperative anteroposterior pelvic radiograph; b: Intraoperative arthrogram after closed reduction with widened medial joint space; $\mathrm{c}$ : Intraoperative arthrogram after open reduction; d: Postoperative MRI during 48 hours, the superior and medial joint space were $3.98 \mathrm{~mm}$ and $2.05 \mathrm{~mm}$, respectively e: Anteroposterior pelvic radiograph 41 months after surgery; the shape and size of the femoral head were larger than that of the contralateral side; left acetabular index is $29^{\circ}$; right acetabular index is $19^{\circ}$; left alsberg angle is $88^{\circ}$; right alsberg angle is $79^{\circ}$ 